\title{
EDUCAÇÃO: FIO CONDUTOR DA SUPERAÇÃO DAS DIFERENÇAS SOCIAIS NO BRASIL
}

\author{
EDUCACIÓN: HILO CONDUCTOR PARA SUPERAR LAS DIFERENCIAS SOCIALES \\ EN BRASIL
}

EDUCATION: GUIDING THREAD FOR OVERCOMING SOCIAL DIFFERENCES IN
BRAZIL

Aureliana da Silva TAVARES ${ }^{1}$

Janine Marta Coelho RODRIGUES ${ }^{2}$

RESUMO: Atitude de intolerância é algo que está se agravando a cada dia em nosso meio social incluindo os espaços escolares. À medida que a sociedade se desenvolve novos grupos surgem com sua forma de pensar, agir e se relacionar e para isso a educação dever acompanhar tais mudanças. Assim, discutiremos a percepção sobre o preconceito no Brasil, desconstruindo estereótipos relacionados às raças e etnias vivenciadas no Brasil do século XXI. Ao longo do discurso apresentaremos algumas características da sociedade brasileira que transpõem o tema intolerância e a inclusão de todos na sociedade. As leis e documentos formais que oferecem subsídios da construção de uma sociedade mais inclusiva perpassaram pelo viés discursivo do texto. A luta por uma sociedade inclusiva que cresce desde o seio das escolas é um dos pontos fundamentais que defendemos e apresentamos no decorrer do artigo.

PALAVRAS-CHAVE: Intolerância. Sociedade. Inclusão.

RESUMEN: Una actitud de intolerancia es algo que se agrava cada día en nuestro entorno social, incluidos los espacios escolares. A medida que la sociedad se desarrolla, surgen nuevos grupos con su forma de pensar, actuar y relacionarse y por eso la educación debe acompañar dichos cambios. Así, discutiremos la percepción del prejuicio en Brasil, deconstruyendo los estereotipos relacionados con las razas y etnias vividas en Brasil en el siglo XXI. A lo largo del discurso presentaremos algunas características de la sociedad brasileña que trasponen el tema de la intolerancia y la inclusión de todos en la sociedad. Las leyes y documentos formales que ofrecen subsidios para la construcción de una sociedad más inclusiva permearon el sesgo discursivo del texto. La lucha por una sociedad inclusiva que nazca del corazón de las escuelas es uno de los puntos fundamentales que defendemos y presentamos a lo largo del artículo.

PALABRAS CLAVE: Intolerancia. Sociedad. Inclusión.

1 Universidade Federal da Paraíba (UFPB), João Pessoa - PB - Brasil. Doutoranda no Programa de PósGraduação em Educação (PPGE/UFPB). Membro do Núcleo de Estudos Projetos e Pesquisas sobre Formação Docente - NEPESF. ORCID: https://orcid.org/0000-0002-1434-8089. E-mail: tavares.aureliana@gmail.com

2 Universidade Federal da Paraíba (UFPB), João Pessoa - PB - Brasil. Professora Titular no Departamento de Habilitações Pedagógicas, do Centro de Educação da UFPB, e credenciada junto ao Programa de Pós-Graduação em Educação (PPGE/UFPB). Coordenadora do Núcleo de Estudos, Projetos e Pesquisas sobre Formação Docente - NEPESF. ORCID: https://orcid.org/0000-0002-9457-9070. E-mail: jmcoelho@ig.com.br

RPGE- Revista on line de Política e Gestão Educacional, Araraquara, v. 25, n. 1, p. 298-310, jan./abr. $2021 . \quad$ e-ISSN:1519-9029 DOI: https://doi.org/10.22633/rpge.v25i1.14795 
ABSTRACT: An attitude of intolerance is something that is getting worse every day in our social environment, including school spaces. As society develops, new groups emerge with their way of thinking, acting and relating. Based on that the education must follow such changes. Thus, we will discuss the perception of prejudice in Brazil, deconstructing stereotypes related to the races and ethnicities experienced in Brazil of the 21st century. Throughout this article we will present some characteristics of Brazilian society that transpose the theme of intolerance and the inclusion of everyone in society. The laws and formal documents that offer subsidies for the construction of a more inclusive society permeated the discursive bias of the text. The struggle for an inclusive society that grows from the heart of schools is one of the fundamental points that we defend and present throughout the article.

KEYWORDS: Intolerance. Society. Inclusion

\section{Introdução}

O artigo discute a percepção sobre o preconceito no Brasil, desconstruindo estereótipos relacionados às raças e etnias desde os tempos remotos.

Apesar de vivermos sob a égide do capitalismo, da concorrência, da hegemonia centralizadora do poder, da insegurança, da luta pela sobrevivência, além de dados alarmantes de desemprego, falta de infraestrutura nas escolas e falta de investimentos na saúde, não podemos cultivar a desesperança e sim a esperança que nos faz acreditar num novo perfil de sociedade brasileira, humano, justo, inclusivo. Assim podemos dizer que

A desesperança das sociedades alienadas passa a ser substituída por esperança, quando começam a se ver com os seus próprios olhos e se tornam capazes de projetar. Quando vão interpretando os verdadeiros anseios do povo. Na medida em que vão se integrando com o seu tempo e o seu espaço e em que, criticamente, se descobrem inacabados (FREIRE, 2007, p. 62).

A esperança fortalece o povo a acreditar na superação, construindo a visão de um mundo melhor, mas de forma consciente. A mudança social ocorrerá através da luta, de expormos o que estamos vivenciando a cada dia.

O Brasil enfrenta a cada dia diversos tipos de preconceitos que vão desde a altos índices de denúncias voltadas aos preconceitos as mulheres, (machismo, misoginia ou sexismo), aos homens (misandria), etnias, os judeus (antissemitismo), aos deficientes físicos, a faixa etária, a aparência (estereótipos), o peso (gordofobia), como dentre outros.

O preconceito existe de forma latente no Brasil, apesar de vivermos lutando por uma sociedade com oportunidades e igualdades. São décadas de luta pelo respeito aos direitos e deveres do povo brasileiro.

RPGE- Revista on line de Política e Gestão Educacional, Araraquara, v. 25, n. 1, p. 298-310, jan./abr. 2021. 
Se analisarmos adentramente, percebemos que esta luta por respeito, dignidade, valorização do ser enquanto pessoa, ser sujeito de suas ações, apresenta as primeiras formalizações legais desde 1948 com a Declaração Universal dos Direitos Humanos. Esta luta ganhou força no Brasil em 1988 com a Constituição Federal quando em suas entrelinhas esclarece, reforça e amplia os direitos fundamentais do povo brasileiro reafirmando que os direitos individuais não poderão ser reduzidos, nem mesmo por meio de Emendas Constitucionais. Assim, a Constituição da República Federativa do Brasil de 1988 apresenta em seu preâmbulo que está

[...] destinado a assegurar o exercício dos direitos sociais e individuais, a liberdade, a segurança, o bem-estar, o desenvolvimento, a igualdade e a justiça como valores supremos de uma sociedade fraterna, pluralista e sem preconceitos, fundada na harmonia social e comprometida, na ordem interna e internacional, com a solução pacífica das controvérsias, promulgamos, sob a proteção de Deus [...] (BRASIL, 1998).

Apesar de haver algumas lacunas em alguns de seus artigos, passando a ser não transparente e com interpretações ambíguas, outros documentos gradativamente deram suportes determinando o rigor da lei superior.

O preconceito precedido pela discriminação, intolerância e desrespeito as atitudes hostis apresentadas por algumas pessoas que vivem em pequenos grupos marginalizados socialmente, economicamente e culturalmente, recebem atitudes agressivas e moralmente depreciativas.

Analisando em quais espaços as pessoas sofrem mais preconceito, foi identificado que a escola estaria no topo com $96,5 \%$. Tais dados foram obtidos através da pesquisa realizada pela Fundação Instituto de Pesquisas Econômicas (Fipe), a pedido do Instituto Nacional de Estudos e Pesquisas Educacionais Anísio Teixeira (Inep) em 2009.

A referida pesquisa foi realizada em 501 escolas públicas de todo o país, que chegou a entrevistar mais de 18,5 mil alunos, pais e mães, professores e funcionários. Os preconceitos apresentados foram de origem étnico-racial, socioeconômico, pessoas com deficiências, gênero, orientação sexual ou territorial.

Destarte, percebemos como as nossas crianças e jovens estão transformando o espaço escolar em um ambiente desfavorável a educação, socialização, respeito e comunhão. Tais resultados também interferem no processo de ensino aprendizagem, na autoestima e crescimento da violência no espaço escolar. Assim, Imbernon (2016, p. 24) esclarece essas mudanças dizendo que 
[...] Em minha opinião, não se pode mudar a educação sem propor seriamente um novo conceito e uma nova mentalidade para analisa-la, e isso já é mais difícil e requer opções políticas que muitas vezes não se verificam. São necessárias muitas mudanças para mudar a educação, com perdão da obviedade. Isso significa perguntar-se como estabelecer relações com a comunidade e com os docentes; a modificação de estruturas, as políticas educacionais, o currículo, o papel dos alunos, a nova forma de aprender para além da escolarização etc. [...].

A escola eventualmente passa por sérias situações de discriminações e intolerância e mudar essa realidade é lutarmos para a construção de uma nova sociedade, um novo olhar para o outro ser capaz de amar, expressas, se relacionar se socializar com sua própria identidade constituindo assim a inclusão social.

O viés que permeia as ações de inclusão sócio educacionais, oportunizando atitudes inclusivas, democraticamente e efetivamente construídas, é um processo educativo que estende a capacidade dos alunos considerados diferentes para além da escola, favorecendo um ambiente social, receptivo e acolhedor a diversidade. Desta forma a Declaração de Salamanca (1994, p. 06), reafirma tais percepções dizendo que

Reafirma o direito a educação de todos os indivíduos. tal como está inscrito na Declaração Universal dos Direitos do Homem de 1948, e renovando a garantia dada pela comunidade mundial na Conferência Mundial sobre Educação para Todos de 1990 de assegurar esse direito, independentemente das diferenças individuais.

O direito a educação está para todos independente das diferenças individuais, infelizmente são anos de luta para que de fato este direito seja reafirmado através das ações sociais e comportamentais. No espaço escolar também é um ambiente constituído, a princípio, para a construção de rupturas de fronteiras existes entre os seres humanos construindo a interação, o respeito e a aceitação do próximo.

O suporte e serviços da área de Educação, da formação continuada, do uso de recursos e materiais didáticos inclusivos para que a escola, através dos seus profissionais, possa, com competência, cumprir as Leis, Resoluções, Decretos dentre outros que regem o tema. Assim, o compromisso constitucional de recusa a qualquer tipo de preconceito ou discriminação dos grupos considerados minorias, são atitudes positivas que favorecem a construção de uma nova vertente educacional - ampla, segura, com respeito e afinidades, passando o tema de inclusão para um processo aprendido, social, dinâmico e educativo que precisa ser continuamente construído e avaliado. 


\section{Brasil, riqueza cultural: causas e consequências}

Os juízos de valores construídos ao longo dos anos pelos grupos sociais "perfeitos" que se enquadra aos seus padrões da maioria da sociedade divergem da construção da nova sociedade em detrimento a classe social, a cultura, a religião, a etnia, a cor da pele, a linguística, a preferência sexual, dentre outros, ganha espaço a cada dia.

O Brasil, país de rico na diversidade cultural, demonstra diversas formas de tratamentos detrimento da sua cultura são trados de forma semelhante. A hegemonia cultural acaba criando uma intolerância pela condição de uma cultura ao se sentir superior à outra, como os casos de etnocentrismo e a xenofobia. O etnocentrismo descreve as atitudes de certos indivíduos que consideram seus hábitos e condutas como superiores aos de outras culturas reforçado pela xenofobia que determina a aversão aos estrangeiros, e surge geralmente por diversos fatores históricos, culturais e religiosos.

No Brasil destacamos diferentes culturas, que em alguns momentos, uma acaba se sobrepõe a outra em virtude de preconceitos devido a miscigenação étnica existente no país. O fato de termos uma variedade cultural, ressaltamos que cada gueto é constituído com seus valores e sua identidade. Assim, Silva (2000, p. 25) explica estes fatores dizendo que

As identidades que são constituídas pela cultura são contestadas sob formas particulares no mundo contemporâneo - num mundo que se pode chamar de pós-colonial. Este é um período histórico caracterizado, entretanto, pelo colapso das velhas certezas e pela produção de novas formas de posicionamento.

Estamos vivendo num momento de transações sócio, politica, econômica e cultural. O Brasil com sua riqueza cultural não poderia ficar de fora dessas lutas por espaço e respeito.

A forma como cada região foi colonizada, desenvolvida industrialmente influencia na cultura de cada região. Tais fatos é um dos fatores que enriquecem os preconceitos e as intolerâncias acreditando, por muitas vezes, acharem que uma cultura seja superior a outras.

Os preconceitos religiosos também são fatores importantes que crescem impondo suas leis e desaculturando uma nação. O rigor, a ordem, o detrimento da autonomia, a doutrina são características fortes que influenciam a vida das pessoas que as seguem. As diferentes religiões devem ser respeitadas independentemente de qual grupo social possa seguir Budismo, Cristianismo, Catolicismo, Protestantismo, Adventismo, Mormonismo, Igreja Ortodoxa, Testemunhas de Jeová, Espiritismo ou Religiões afro-brasileiras. Afinal, o livre arbítrio de cada um deve ser respeito quando fazemos parte de uma sociedade democrática. Assim dizemos que 
A coexistência da ampla diversidade étnica, linguística e religiosa em solo brasileiro coloca a possibilidade da pluralidade de alternativas. De certa forma, é como se o plural que se constata, seja no convívio direto, seja por outras mediações, evidenciasse e ampliasse o plural que potencialmente está em cada um. Assim, o princípio de liberdade se afirma nas possibilidades múltiplas de cada um, na polissemia subjetiva que permite escolhas e novos encontros (BRASIL, 1997, p. 17).

Sabemos, que por trás da religiosidade, está a intolerância quando uma pessoa não aceita a diversidade religiosa da outra e acaba construindo juízos de valor sobre outras crenças, muitas vezes sem fundamento, achando a sua religião superior as demais. Tais atitudes criam diversos conflitos e em alguns países, acabam influenciando a organização sócio-política-econômica de um país em relação as guerras religiosas.

O Brasil conhecido pela pluralidade cultural, também sofre com preconceitos raciais que se relacionam à etnia. A raça e seus aspectos físicos, por exemplo, são motivos de desrespeito e desvalorização a cor da pele, os traços físicos, o cabelo entre outros. Isso pode ocorrer entre pessoas de diferentes aspectos de cor de pele, sendo mais comum entre brancos e negros, donde os primeiros, decorrentes de aspectos históricos, se sentem superiores aos outros. Assim,

as culturas são produzidas pelos grupos sociais ao longo das suas histórias, na construção de suas formas de subsistência, na organização da vida social e política, nas suas relações com o meio e com outros grupos, na produção de conhecimentos, etc. A diferença entre culturas é fruto da singularidade desses processos em cada grupo social (BRASIL, 1997, p. 16).

Devido o processo de colonização, outro aspecto também nos chama a atenção, e, é influenciado com grande preconceito e intolerância, são as questões linguísticas de nosso país. Determinado grupo social e regional com seus sotaques e vocabulários diferentes.

No Brasil, notamos muito preconceito linguístico entre as diversas regiões do país, e inclusive dentro de cada uma das macro regiões, inclusive entre moradores das capitais e interioranos, uma vez que existem diversos sotaques oriundos de diferentes imigrações e etnias, em cada um destes espaços geográficos. Paulo Freire (2016) dizia que não havia uma cultura errada, mas uma cultura diferente.

Com o passar dos anos evidenciamos com mais frequência à constituição de novos grupos famíliares não só no Brasil, mas no mundo. Analisando essa temática das relações sexuais, das mais variadas formas de construção familiar, percebemos que o preconceito sexual visto por alguns como um tabu, ainda é motivo de comentários, rejeições, intolerância. 
As preferências sexuais de cada indivíduo - homofobia ou heterofobia são motivos de grandes preconceitos sociais, verbais, atitudinais chegando a alguns casos em agreções físicas. Podemos descrever que o primeiro, homofobia, refere-se ao preconceito desenvolvido sobre as pessoas que possuam relações homo afetivas, ou seja, entre pessoas do mesmo sexo. Segundo o Estatuto da Criança e do Adolescente os critérios para início da adoção são

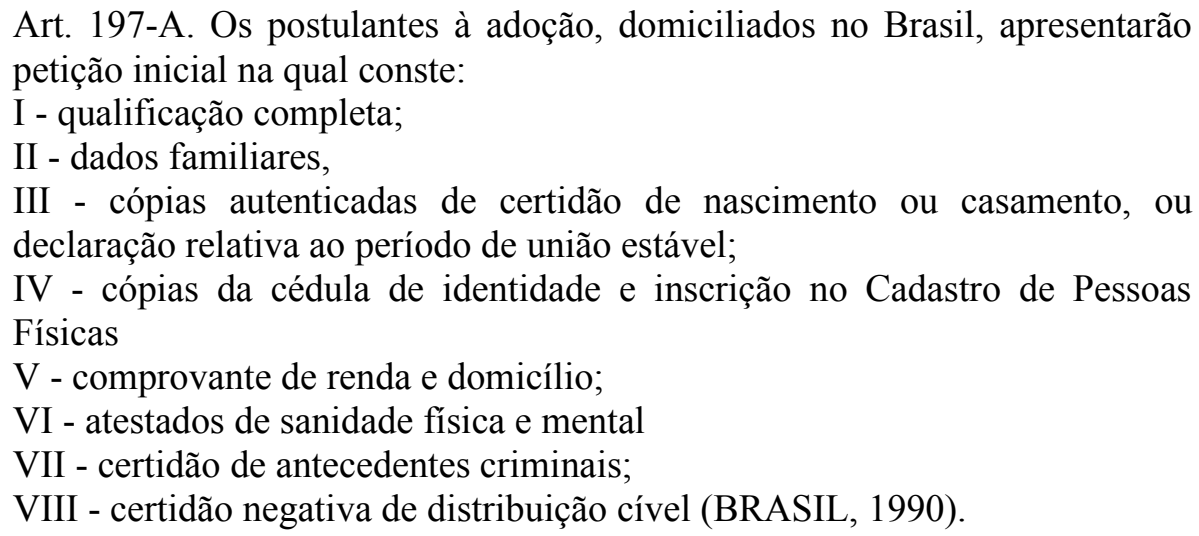

No Brasil, ainda não existe uma lei para a liberação legal da adoção de crianças por homofóbicos, mas tramita na Câmera dos Deputados uma proposta de lei Estatuto da Família - 6.583-A/2013 do Sr. Anderson Ferreira que diz

\begin{abstract}
A sociedade livre, justa e solidária e a dignidade da pessoa humana, sem preconceitos de origem, raça, sexo, cor, idade e quaisquer outras formas de discriminação, preconizados pela Constituição Federal, assim como os princípios da igualdade e liberdade, revelam um sistema que deve ser visto à luz das transformações enfrentadas na sociedade, de modo a reconhecer novos modelos de família.

O homossexual não é cidadão de segunda categoria. A orientação ou condição sexual não diminui direitos e, muito menos, a dignidade da pessoa humana. As uniões homoafetivas, não se pode negar, fazem parte da realidade social e, por isso, devem receber a mesma proteção garantida às uniões heteroafetivas (BRASIL, 2013. p. 134).
\end{abstract}

Muito ainda deve ser feito para que conceda a liberação da adoção por grupo de familiares homoafetivas. Apesar de vermos diariamente novas formações familiares, a legalização da adoção por esse grupo ainda não existe no Brasil.

Da forma que existem fortes preconceitos pela relação de pessoas do mesmo sexo a heterofobia exprime o preconceito de determinados grupos que apresentam oposição entre as relações heterossexuais, ou seja, entre pessoas de sexo oposto.

Com base nessa explanação, percebemos que muitos desses fatores têm influenciado o espaço escolar causando grandes conflitos internos e externos. A nova roupagem da escola 
está vinculada a diversos grupos minoritários que a cada dia vem ganhando espaço e lutando por visibilidade, vez e voz. Assim,

\begin{abstract}
Historicamente, registra-se dificuldade para se lidar com a temática do preconceito e da discriminação racial/étnica. O País evitou o tema por muito tempo, sendo marcado por "mitos" que veicularam uma imagem de um Brasil homogêneo, sem diferenças, ou, em outra hipótese, promotor de uma suposta "democracia racial". Na escola, muitas vezes, há manifestações de racismo, discriminação social e étnica, por parte de professores, de alunos, da equipe escolar, ainda que de maneira involuntária ou inconsciente. Essas atitudes representam violação dos direitos dos alunos, professores e funcionários discriminados, trazendo consigo obstáculos ao processo educacional, pelo sofrimento e constrangimento a que essas pessoas se vêem expostas (BRASIL, 1997, p. 20).
\end{abstract}

A escola precisa está preparada para lidar com essa conjuntura social buscando o equilíbrio das diferenças, possibilitando um espaço rico, criativo, produtivo e inclusivo, que as diferenças se tornem subsídios de crescimento, respeito e possibilidades de ir mais além nas relações pessoais e sociais

\title{
A participação social na luta contra a intolerância
}

Analisando o termo sociedade como sinônimo de movimento, de mudanças, busca e adaptação ao novo, percebemos a instabilidade ou fortalecimento acelerado de grupos sociais com isso crescem mais estudos que ajudem a aceitar essa nova forma de constituição afetiva nas relações humanas.

As novas tendências das relações familiares, da valorização das classes sociais, da cultura globalizada, das multifaces das religiões brasileiras, das raças dentre outros grupos minoritários, enfrentam as lutas por mais espaço na sociedade, reivindicando seus direitos e deveres como cidadão brasileiro. Tais fatos requerem um estudo aprofundado através do desenvolvimento de pesquisas que somem a essa "nova" característica da sociedade. Um dos pontos relevantes nessa luta pela inclusão, para que a diversidade seja uma soma positiva de crescimento, de trocas de experiências, criatividade, sabedoria, valorização e satisfação seria a construção uma educação inclusiva.

A educação inclusiva surgiu no Brasil na década de 90 com os documentos norteadores das Conferências Mundiais de Educação Especial e em 1994 foi proclamada a Declaração de Salamanca. Tais documentos influenciaram a Lei 9394/96 - de Diretrizes e Base da Educação - LDB, que afirma sendo

RPGE- Revista on line de Política e Gestão Educacional, Araraquara, v. 25, n. 1, p. 298-310, jan./abr. $2021 . \quad$ e-ISSN:1519-9029 
Art. $5 \mathrm{O}$ acesso à educação básica obrigatória é direito público subjetivo, podendo qualquer cidadão, grupo de cidadãos, associação comunitária, organização sindical, entidade de classe ou outra legalmente constituída e, ainda, o Ministério Público, acionar o poder público para exigi-lo (BRASIL, 1996).

A Educação é um dos pontos fundamentais para que a inclusão social sai do papel passando como firmamento ideológico da construção de uma sociedade para todos, onde possamos de fato exercer nosso papel de cidadão.

É trabalhando em salas de aula com a valorização dos grupos minoritários, realização de atividades reflexivas, dialogada, onde cada aluno possa expressar o que sente, o que pensa e assim em grupo buscar trabalhar uma nova ideologia de aceitação, respeito, confiança e o compromisso de desenvolvimento de ações inclusivas.

As ações inclusivas que destacamos nascem do micro para o macro. É aceitando as pessoas que estão mais próximas de nós, valorizando seu potencial, independente da sua forma de ser, estar ou crer, que impedem que as questões pessoais não se tornem uma barreira ideológica da exclusão.

A participação de debates não apenas em centros educacionais de Educação Básica, a participação efetiva do Ensino Superior, pedem destaque quando almejamos uma participação mais contundente para uma aceitação das diferenças. A instrução, formação, conhecimento acadêmico deslumbrará de forma ponderada, um diálogo rico, preciso e científico. A diversidade existe há séculos entender e respeitar esse público excluído é oportunidade de construir socialmente a inclusão.

A historicidade, esclarecimentos de suas raízes ajudarão a entender o quanto esse público que faz parte dos grupos minoritários, sofrem e clamam por aceitação, respeito e espaço digno na sociedade para mostrar sua capacidade, usufruindo seu direito de cidadão brasileiro.

Trabalhando com base nesta perspectiva, de promover debates em todos os níveis da educação, acreditamos que disseminar processos inclusivos é um fator primordial para minimizar com o preconceito latente no Brasil. A Educação ainda é a única arma que temos para lutar e construir uma sociedade para todos.

O trabalho em equipe com educadores, equipe de gestão, apoio das leis inclusivas e a participação efetiva dos debates acadêmicos avançará dando lugar a estudos centrados reveladores da importância das classes sociais se unirem tanto na esfera da socialização, participação quanto da produção e reprodução social. 
O rompimento das barreiras atitudinais, contemplando a existência de outras relações co-extensivas, favorecem a invisibilidade desses grupos minoritários acentuavam os preconceitos e exclusões nos espaços sociais dentre eles o escolar. Tais atitudes materializavam em múltiplas formas a violência chegando a evasão escolar e outros traumas individuais gerando a revolta de alguns.

O desenvolvimento de um trabalho que almeje uma sensibilidade cada vez maior da educação inclusiva, problematizadora que viabilize a compreensão das múltiplas formas de viver em sociedade é o que deseja esses grupos com o apoio dos movimentos sociais.

As discussões desenvolvidas de forma crítica a violência, ao preconceito, a intolerância que vemos em nossa vida cotidiana, inclusive aquelas que ocorrem nas ruas, em nossas casas, na escola, no trabalho e na mídia de forma ampla possa ser realizada.

Com a visibilidade da violência, do preconceito, da intolerância aos grupos minoritários, percebemos a proliferação dos movimentos sociais de firmação identitária em sociedades que viviam a silenciar as diferenças, os particularismos e as singularidades.

As participações dos movimentos sociais oferecem suportes para que tais grupos não percam seus ideais e lutem com objetividade por mais espaço na sociedade.

\section{Considerações finais}

Não podemos deixar de perceber a importância de desenvolver ensaios com a temática do preconceito e intolerância que circundam nosso cotidiano. Percebemos ao longo da leitura, que a nossa sociedade se subdivide em vários grupos que lutam por visibilidade. Infelizmente a violência encontra-se presente em vários setores de sua vida, principalmente no espaço escolar que impedem desses grupos minoritários ser mais ativo e participativo na sociedade.

Contundentemente, as violências sofridas por esses grupos, em alguns casos, estão gerando outros atos violentos. O preconceito é uma ação que causa dano a outras pessoas negando a autonomia do ser quanto cidadão de um país.

Percebemos nas entrelinhas do artigo que a ação preconceituosa pode gerar problemas psíquicos que acompanharão os indivíduos vitimizados pelo preconceito em suas vidas deixando-os reprimidos ou agressivos. Os danos causados pelas atitudes preconceituosas regadas de intolerâncias podem causar danos materiais, fisiológicos ou psicológicos na vítima. Assim, em algumas vezes não é tão obstantes presenciarmos atitudes desumanas, com atos de rejeição, depreciação, indiferença, discriminação, desrespeito, punições exageradas gerando atos graves de violência. 
O desenvolvimento de um discurso inclusivo, efetivo e amplo não apenas na Educação Básica. Assim, as pessoas ou grupos minoritários que se sentirem ofendidos poderão expressar seus anseios e conscientizar para que se pratique a inclusão frente a tanta diversidade.

O trabalho em equipe de conscientização certamente oportunizará o debate contra pequenos gestos de violência que algumas vezes são tolerados, mas que poderão se ampliar e isso, oportuniza reverter tais atitudes de exclusão, construindo um discurso que reverteria alternativas com base na quebra de preconceito.

As pessoas que constituem uma sociedade precisam ter como propostas atitudes inclusivas a partir do amadurecimento de uma postura em que as diferenças sejam respeitadas. Não devemos pensar só em prevenir situações de violência ou como tornar o ambiente escolar mais acolhedor e solidário. Construir uma visão de que, uma pessoa independente de crença, de raça, de sexo, de situação socioeconômica, de cultura ou até mesmo de idade, precisa lutar por seus direitos, diante da ideia de que todo ser humano é sujeito de direitos e merece ser respeitado e esta visão só poderá ser construída através de uma educação verdadeira, crítica, problematizadora.

\section{REFERÊNCIAS}

APPLE, M. W. Educando à direita: mercados, padrões, Deus e desigualdade. Trad. Dinah de Abreu Azevedo; ver. técnica de José Eutáquio Romão. São Paulo: Cortez, 2003.

BANDEIRA, L.; BATISTA, A. S. Preconceito e discriminação como expressões de violência. Rev. Estud. Fem., Florianópolis, v. 10, n. 1, p. 119-141. 2002. ISSN 1806-9584. DOI: https://doi.org/10.1590/S0104-026X2002000100007

BAUMAN, Z. Em busca da política. Trad. Marcos Penchel. Rio de Janeiro: Jorge Zahar, 2000 .

BRASIL. Constituição (1988). Constituição da República Federativa do Brasil. Brasília, DF: Senado, 1988.

BRASIL. Lei n. 8.069, de 13 de julho de 1990. Dispõe sobre o Estatuto da Criança e do Adolescente e dá outras providências. Diário Oficial da União: Seção 1, Brasília, DF, p. 13563, 16 jul. 1990.

BRASIL. Lei n. 9.394, de 20 de dezembro de 1996. Lei de Diretrizes e Bases da Educação Nacional. Diário Oficial da União: Seção 1, Brasília, DF, n. 248, p. 27833, 23 dez. 1996.

BRASIL. Projeto de lei Estatuto da Família n. 6.583-A, de 2013 do Sr. Anderson Ferreira. 2013. Disponível em: https://www.camara.leg.br/proposicoesWeb/prop_mostrarintegra;jsessionid=47FC186CDB5C 
27E515DF6EEB0712A562.proposicoesWeb2?codteor=1398893\&filename=Avulso + PL+6583/2013. Acesso em: 16 ago. 2020.

BRASIL. Secretaria de Educação Fundamental. Parâmetros curriculares nacionais: pluralidade cultural, orientação sexual. Brasília: MEC/SEF, 1997. Disponível em: http://portal.mec.gov.br/seb/arquivos/pdf/livro101.pdf. Acesso em: 15 ago. 2020.

FREIRE, P. Educação como prática da liberdade. 30. ed. Rio de Janeiro: Paz e Terra, 2007.

FREIRE, P. Pedagogia da autonomia: saberes necessários à prática educativa. 34. ed. São Paulo: Paz e Terra, 1996. (Coleção Leitura)

FREIRE, P. Pedagogia da esperança: um reencontro com a pedagogia do oprimido. 3. ed. Rio de Janeiro: Paz e Terra, 1992.

FREIRE, P. Pedagogia da tolerância: organização, apresentação e notas Ana Maria Araújo Freire. 5. ed. São Paulo: Editora Paz e Terra, 2016.

Fundação Instituto de Pesquisa Econômica - FIPE. Disponível em: http://www.fipe.org.br/. Acesso em: 10 ago. 2020.

RICHARDSON, R. J. (Org.). Exclusão, inclusão e diversidade. João Pessoa: Editora Universidade da UFPB, 2009.

RODRIGUES, I. E. Educação inclusiva: um desafio para o século XXI. Série Estudos Reunidos. Jundiaí, Paco Editorial. 2016. v. 16.

RODRIGUES, J. M. C. (Org.). Formação docente: contribuição do ideário de Paulo Freire. João Pessoa: Sal e Terra, 2006.

RODRIGUES, J. M. C.; GEGLIO, P. C. (Org.). Contribuições das ideias de educadores brasileiros para a formação docente. João Pessoa: Editora do CCTA, 2016.

RODRIGUES, J. M. C.; SIMÔES, M. L. (Org.). Um passado sempre presente no fazer pedagógico. João Pessoa: Fox Editora, 2015.

SILVA, T. T. (Org.). Identidade e diferença: a perspectiva dos estudos culturais. Petrópolis, RJ: Vozes, 2000.

TAVARES, A.; BARREIRO, A. M. O papel do educador na sociedade pós-moderna. Revista on line de Política e Gestão Educacional, Araraquara, v. 21, n. esp. 2, p. 1227-1238, nov. 2017. DOI: http://dx.doi.org/10.22633/rpge.v21.n.esp2.2017.10162 


\section{Como referenciar este artigo}

TAVARES, A. S.; RODRIGUES, J. M C. Educação: fio condutor da superação das diferenças sociais no Brasil. Revista on line de Política e Gestão Educacional, Araraquara, v. $25, \quad$ n. $1, \quad$ p. $298-310$, jan./abr. 2021. e-ISSN:1519-9029. DOI: https://doi.org/10.22633/rpge.v25i1.14795

Submetido em: 25/08/2020

Revisões requeridas em: $26 / 10 / 2020$

Aprovado em: 15/11/2020

Publicado em: 02/01/2021 